62

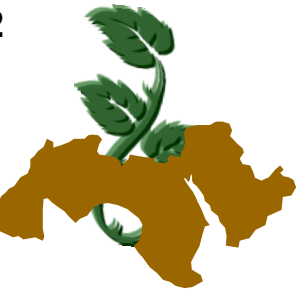

Arab Univ.

J. Agric. Sci., Ain Shams Univ., Cairo, 18(1), 49-62, 2010

\title{
INFLUENCE OF MOLASS APPLICATION ON SOME SOIL HYDRAULIC CHARACTERISTICS AND INFILTRATION RATE, RELATED TO THE SOIL STRUCTURE
}

\author{
Ati, Alaa S. ${ }^{1, a}$ and F. Younan, Taghreed ${ }^{1}$ \\ 1. Soil and Water Dep., Collage of Agricultural- University of Baghdad, Baghdad, Iraq. \\ a. E-mail:alaasalih2008@yahoo.com
}

Keywords: Water transport function [Penetrability, Sorptivity and infiltration rate], Contact angle, Soil surface free energy, Soil structure and Molass

\begin{abstract}
A laboratory study was performed to evaluate the role of Molass using four levels $(C=0,10,20$ and $40 \mathrm{~g} \mathrm{~kg}^{-1}$ ) on the water transport function [namely, penetrability $(\lambda)$, sorptivity $(S)$ and infiltration rate $(i)$ ] during transient flow in horizontal infiltration in Sandy loam soil incubated with Molass at $25 \pm 2{ }^{\circ} \mathrm{C}$ and $80 \%$ relative moisture content at $33 \mathrm{Kpa}$. For 60 days. Boltzmann transformation $\left(\lambda=x / \frac{1}{t} / 2\right)$ was used to esitmate penetrability by fitting the wet front distance $X$ vs. square root of time $(t)$. Equation of Philip (1957) $\left(I=S t^{1 / 2}\right)$ was used to estimate sorptivity $(S)$ by fitting cumulative
\end{abstract}

depth of water observed (I) vs. $t^{1 / 2}$. Infiltration rate $(i)$ was calculated using equation $\left(i=1 / 2 S t^{-1 / 2}\right)$. The contact angle $(\alpha)$, soil surface free energy $\left(\gamma_{s}\right)$ were measured and calculated for all soil treatments. We also studied the effect of Molass on aggregate stability from the values of Mean Wight Diameter (MWD) and Geometric Mean Diameter (GMD). Results showed significant response and decrease in all study water transport functions $[(\lambda),(S)$ and $(i)]$ with distance $30 \mathrm{~cm}$ of wetting front advance in end time with increasing the levels of Molass from 0.0 to $40 \mathrm{~g} \mathrm{~kg}^{-1}$. Value of contact angle increased from 49.54 to 76.17 , while the value of soil surface free energy decreased from 135.9 to 76.8 ( $\mathrm{m} \mathrm{N} \mathrm{m}-1$ ).

The addition of Molass played very important role in aggregate stability according to the value of MWD and GMD. 